Louisiana State University

LSU Digital Commons

1979

\title{
Effect of Prior Performance Experience Before Audiences on a Dominant and Nondominant Motor Response.
}

Nancy Lucinda Hollifield

Louisiana State University and Agricultural \& Mechanical College

Follow this and additional works at: https://digitalcommons.Isu.edu/gradschool_disstheses

\section{Recommended Citation}

Hollifield, Nancy Lucinda, "Effect of Prior Performance Experience Before Audiences on a Dominant and Nondominant Motor Response." (1979). LSU Historical Dissertations and Theses. 3440.

https://digitalcommons.Isu.edu/gradschool_disstheses/3440

This Dissertation is brought to you for free and open access by the Graduate School at LSU Digital Commons. It has been accepted for inclusion in LSU Historical Dissertations and Theses by an authorized administrator of LSU Digital Commons. For more information, please contact gradetd@lsu.edu. 


\section{INFORMATION TO USERS}

This was produced from a copy of a document sent to us for microfilming. While the most advanced technological means to photograph and reproduce this document have been used, the quality is heavily dependent upon the quality of the material submitted.

The following explanation of techniques is provided to help you understand markings or notations which may appear on this reproduction.

1. The sign or "target" for pages apparently lacking from the document photographed is "Missing Page(s)". If it was possible to obtain the missing page(s) or section, they are spliced into the film along with adjacent pages. This may have necessitated cutting through an image and duplicating adjacent pages to assure you of complete continuity.

2. When an image on the film is obliterated with a round black mark it is an indication that the film inspector noticed either blurred copy because of movement during exposure, or duplicate copy. Unless we meant to delete copyrighted materials that should not have been filmed, you will find a good image of the page in the adjacent frame.

3. When a map, drawing or chart, etc., is part of the material being photographed the photographer has followed a definite method in "sectioning" the material. It is customary to begin filming at the upper left hand corner of a large sheet and to continue from left to right in equal sections with small overlaps. If necessary, sectioning is continued again-beginning below the first row and continuing on until complete.

4. For any illustrations that cannot be reproduced satisfactorily by xerography, photographic prints can be purchased at additional cost and tipped into your xerographic copy. Requests can be made to our Dissertations Customer Services Department.

5. Some pages in any document may have indistinct print. In all cases we have filmed the best available copy.

\section{University \\ Microfilms International}


HOLLIFIELD, NANCY LUCINDA

EFFECT OF PRIOR PERFORMANCE EXPERIENCE BEFORE AUDIENCES

ON A DOMINANT AND NONDOMINANT MOTOR RESPONSE

The Louisiana State University and Agricultural and Mechanical Col.

PH.D. $\quad 1979$

University

Microfilms

International 300 N. Zeeb Road, Ann Arbor, MI $48106 \quad 18$ Bedford Row, London WCIR 4EJ, England 


\title{
Effect of Prior Performance Experience Before \\ Audiences on a Dominant and Nondominant \\ Motor Response
}

\author{
A Dissertation \\ Submitted to the Graduate Faculty of the \\ Louisiana State University \\ Agriculture and Mechanical College \\ in partial fulfillment of the \\ Doctor of Philosophy
}

in

The Department of Health, Physical and Recreation Education

Nancy Lucinda Hollifield

B.A., Furman University, 1972

M.Ed., The UnIversity of Georgia, 1973

December, 1979 
Dedicated to Brian Allyn Hollifield 


\section{ACKNOWLEDGEMENTS}

The author wishes to express her appreciation to Dr. Evelyn G. Hall and $\mathrm{Dr}$. Jack K. Nelson for their professional guidance in the preparation of this dissertaion. Dr. Hall's example of scholarship with Integrity has been a source of inspiration throughout the development of this research. Dr. Nelson's wisdom, wit and sense of fairness have been invaluable to this project and throughout my doctoral studies.

To the other members of my committee, Dr. Amelia Lee, Dr. Richard Magi11, Dr. Jerry Thomas and Dr. Perry Prestholdt, I am indebted for their contributions. Special acknowledgement is due to Gabie E. Church, for her patience, statistical assistance and encouragement.

Most importantly, I would like to acknowledge the contributions made to this effort by my mother, Mrs. J. T. Hollifield, who taught me that my accomplishments are limited only by my efforts. My nephew, Brian Allyn Hollifield, is also deserving of special thanks. Certainly he helped keep my studies in proper perspective.

To my friends at L.S.U. who provided support and encouragement throughout the past two years, I am forever indebted. For my new friends in Wilmington who have made it all worthwhile, I am sincerely grateful. 


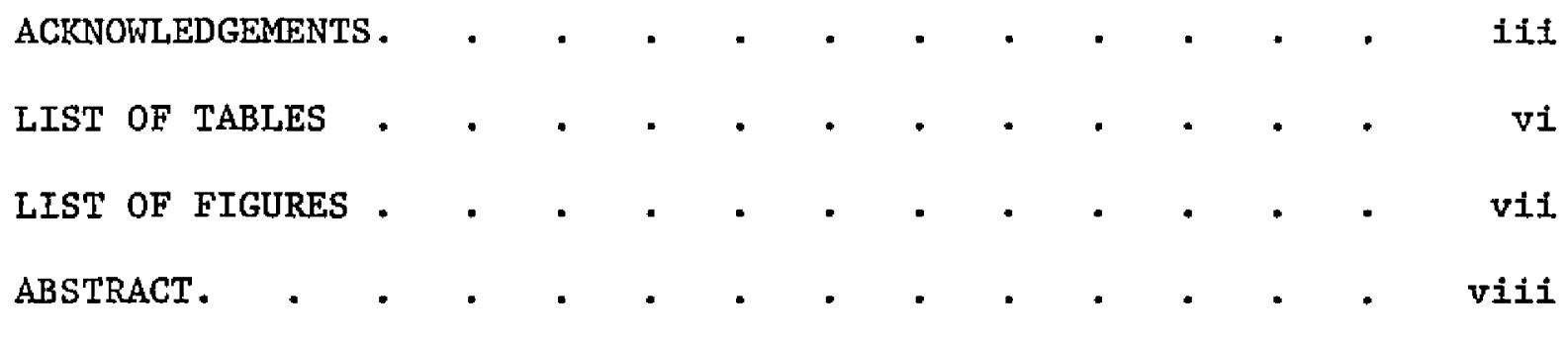

Chapter

I. INTRODUCTION

Early Research : . . . . . . . . 1

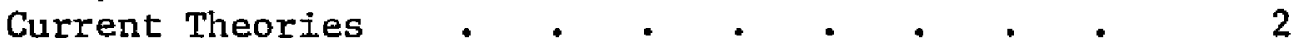

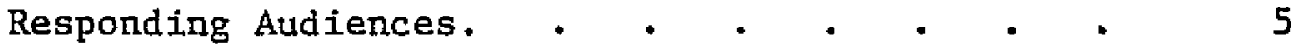

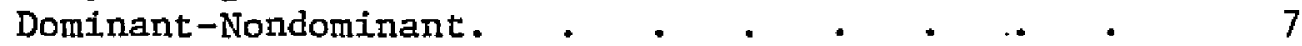

Statement of the Problem. . . . . . . 99

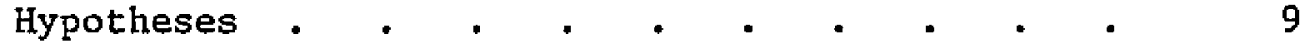

Operational Definitions . . . . . . . . . 10

Limitations . • . . . . . . . . .

Significance of the Study . . . . . . . 11 ,

II. METHODS * . . . . . . . . . . 13

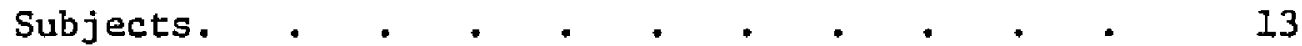

Rotary Pursuit Task . . . . . . . . . . 14

Selection of Deperident Motor Performance Variable $\quad 14$

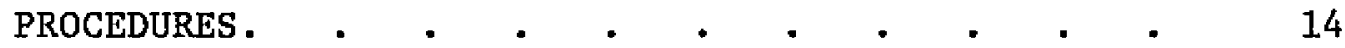

Performance Procedures . . . . . . . 15

Evaluative Audience Condition . . . . . 15

No Audience Condition . . . . . . . . . 16

Design and Data Analysis. $. \quad . \quad . \quad . \quad . \quad . \quad 17$

III. RESULTS . . . • . • . . . . . . 18

Performance Experience Questionnaire. . . . . I8

Dominant Response Development . . . . . 19

Statistical Analysis. . . . . . . . 20

Causal Perception Questionnaire . . . . . 21 
IV.

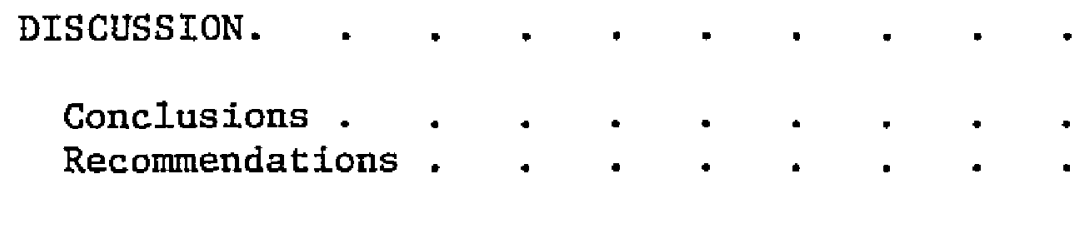

APPENDIX A. Performance Experience Questionnaire . . 38

APPENDIX B. Gausal Perception Questionnaire. . . . 42

APPENDIX C. Analysis of Variance Means . . . . . 45

APPENDIX D. Responses to Causal Perception Questionnaires 49 


\section{LIST OF TABLES}

Table

Page

1. 2 (Experience) $\times 2$ (Task Dominance) $\times 2$ (Audience) ANOVA. 20

2. Mean Scores of Novel and Learned Task Groups - . 20

3. Newman-Kuels Test for Task x Audience Interaction . 21 


\section{LIST OF FIGURES}

Figure

Page

1. The Effect of Task $x$ Audience Interaction on Mean Rotary Pursult Scores.

vii 
ABSTRACT

The purpose of the present study was to determine if the prior performance experience of children was a mediating factor in their performance of a dominant or novel task in an audience or no audience situation. The 80 , 9-year-old boys were divided into experienced $(n=40)$ and nonexperienced $(n=40)$ groups based on their prior youth sport experience and the absence of any performance experience before a formal audience. Half of each group learned a rotary prusuit task until they could perform the task with at least $60 \%$ accuracy, insuring that the correct response was dominant. The other half of each group did not practice the task. Groups were agin divided for task performance in an audience or no audience situation such that the following treatments were observed for both experienced and nonexperienced groups: dominant task, no audience; dominant task, evaluative audience; novel task, no audience; novel task, evaluative audience.

Task performance for each subject was five, 20-second trials on the photoelectric rotary pursult task. The mean score of each set of five was utilized for data analysis. An audience of four passive adults was present In each audience condftion and made evaluative notations following each performance.

Results of a 2 (experience) $\mathrm{x} 2$ (task dominance) $\mathrm{x} 2$ (audience) ANOVA failed to support Zajonc's (1965) social facilitation theory. Rather 
than confirm that performance of a novel task was inhibited, and that of a dominant well-learned task was facilitated, the well-learned task was inhibited by the presence of an evaluative audience while performance of a novel task was enhanced. Results of a causal perception questionnaire were offered as an explanation of these findings. Data from this study, which suggested that one's response to an audience is not a well conditioned response in young boys, further failed to support Cottrell's (1968) modification of the Zajonc (1965) theory. No differential experience effects were evident either as a main effect or in interactions, indicating that an aversive response to an audience is not a well conditioned response in young boys. 


\section{CHAPTER I}

\section{INTRODUCTION}

The presence of an audience and its effect during the performance of a task is a curious social phenomenon. This phenomenon, concerned with performance in the presence of others, has been labeled social facilitation.

Both social psychologists and sport psychologists have been involved in research studying the effect of others on the performance of cognitive and motor tasks. The social facilitation phenomenon has been investigated, not only relative to the effects of audience observation on performance, but also relative to coactors, others engaged in Independent performance of the same activity at the same time. The present study is concerned with spectators as social facilitators. Early Research

Attempts to determine the effects of an audience on motor performance occurred as early as 1897, when Triplett conducted studies involving fishing-reel winding and cycling tasks. His conclusion, that the presence of others facilftated task performance, spawned other studies which both confirmed and contradicted his findings.

Abel (1938), Allport (1920, 1924), BurrI (1931), Dashiell (1930), Gates (1924, Moore (1917), Pessin (1933), Pessin and Husband (1933) and Travis (1925) were among the early researchers who considered the effects of varlous audience conditions on task performance. Although the results of these studies were somewhat vague, the researchers concluded, 
generally, that performance on simple tasks was better in the presence of others, whlle performance of tasks requiring more complex judgment and problem solving was better alone. Perhaps the ambiguity of the results of the early studies was cause for the waning interest in social facilitation after the early $1930^{\prime}$ s. Current Theories

Revitalfzation of research examining the phenomenon of social facilitation has been based on Zajonc's (1965) adaptation of the HullSpence drive theory. The theory (Beck, 1978) implies that a source of drive (D) energizes habit strength $\left({ }_{S} H_{R}\right)$ and, thereby, increases excitatory potential (E) such that:

$$
E=\mathrm{S}_{\mathrm{R}}^{\mathrm{H}} \times \mathrm{D}
$$

Accordingly, Zajonc postulated that the presence of an audience or coactors increases the performer's drive level (D), enhancing the emission of dominant responses $\left(\mathrm{S}_{\mathrm{R}}\right)$ and increasing performance (E). Facilitation of performance results if the correct response is dominant, whereas performance is hindered if the incorrect response is dominant. Zajonc's theory suggests that the performance of simple tasks, involving a small number of correct responses, should be of higher quality, or more efficient, with high drive than low. The correct response would be the dominant response and performance would be facilitated.

Spence and Spence (1966) extended Zajonc's theory to the learning of complex tasks, and suggested that during early learning stages incorrect responses are generally dominant. As learning progresses, however, the habit strength of correct responses causes their position to become 
dominant. Thus, increased drive hinders early learning of a complex task and facilitates Iater performance of the well-learned task. Many studies (Burwitz \& Newel1, 1972; Carment \& Latchford, 1970; Cottrell, Rittle \& Wack, 1967; Ganzer, 1968; Hunt \& Hillery, 1973; Martens, 1969b; Martens \& Landers, 1969; Zajonc \& Sales, 1966) have obtained results consistent with Zajonc's theory that the physical presence of others results in an increased drive level of performers. However, an equivalent number of studies (Bergum \& Lehr, 1962, 1963; Bird, 1973; Carment, 1970b; Chevrette, 1968; Cox, 1966; Haas \& Roberts, 1975; Hall, 1977; Hartnett, Gottleib \& Hayes, 1977; Livingston., Landers \& Dorrance, 1974; Paulus \& Corne1ius, 1974; Roberts, 1972; Singer, 1970; Wankel, 1972) have been either nonsupportive of Zajonc's theory or inconclusive. Williams (1975) attributed these diverse findings to the many different ways in which social conditions were defined and manipulated, the various tasks that were utilized and the different subject characteristics that were considered from study to study. Moreover, Williams noted an inconsistency in the interacting influences of extraneous controlled or uncontrolled variables.

One nonsupportive study (Cottre11, Rittle, Sekerak \& Wack, 1968) found that while an attending audience facilitated performance, a blindfolded audience did not. This suggested that the mere presence of others was not sufficient to increase drive. Cottrell (1968) proposed that the audience's abiltty to evaluate performance determined the performers anticipation of positive and negative outcomes, and strongly emphasized that the evaluative potential of the audience was the drive related factor. Cottrell viewed this expectation of evaluation as a learned 
source of drive, serving as a source of facilftation. Thus, an evaluative audience increases the subject's drive level because the individual, from past experience, learns to associate a critical audience, or puntshment in the presence of others, with evaluative situations. As the number of such occasions increases, observers become, through classical conditioning, stimuli for drive arousal as performers anticipate evaluation by others.

Research supporting Cottrel1's theory of the evaluative observer as a social facilitator was conducted by Criddle (1971), Henchy and Glass (1968), Klinger (1969), Paulus and Murdoch (1971) and Sasfy and Okun (1974). These studies concluded, generally, that the mere presence of others was not sufficient to produce the phenomenon of social facilitation, and that the evaluative property of an audience was a learned source of drive based on previous experience. For example, Henchy and Glass (1968) found that the emission of dominant responses was greater for performance before an expert audience than before a non-expert audience or in a no audience situation.

Weiss and Mtller (1.971) extended Cottrell's learned drive theory by stating that drive induced by an observing audience is an aversive drive, similar to frustration and anxiety. This proposal was tested by Lombardo and Catalano (1975) who attempted to classically condition an aversive drive to an audfence by having a subject fail at a task in front of an audience. No differences in performance were found between those groups failing a first task and those who did not. The failure of this attempt to classically condition a secondary drive to an audience was partially attributed to procedural failure, however, the study did 
clearly indicate the drive arousing properties of expert audience manipulation.

Difficulties in drive conditioning might be best avoided by a more direct approach to evaluating the role of the audience as a learned source of drive. Subjects having no prior experience with audience evaluation would not reflect this drive, as its strength is a function of the number of times this social condition has occurred. The energized response tendency would, however, be established in those who had prior experience performing before an evaluative audience.

Responding Audiences

An attempt to further refine the Cottrel1. (1968) theory, which defines the drive properties of an audience in terms of its evaluative potential, involves performance before a verbally responding audience. This consideration of a characteristic more applicable to a real-life motor skill performance has been, for the most part, ineffective.

Early studies considering positive and negative responses were conducted by Gates (1924) and Laird (1923). Gates discovered onIy a slightly favorable difference when an audience responded favorably to task performance. Laird evaluated performance on four motor tasks in the presence of a passive audience and one which razzed subjects before performance. He concluded that razzing impalred performance on the task.

More recent studies have failed to support either the hypothesis that a responding audience facilitates performance more than a passive or no audience condition, or the hypothesis that a positive response facilitates performance more than a negative response. Experimental design utflized appears to be somewhat responsible for the inconclusive 
results of many of these studies.

Singer (1965) in testing athletes and non-athletes before spectators responding in a "natural" way, found that spectators' responses varfed from subject to subject. This inconsistency facilitated performance for some subjects and inhibited performance for others. Therefore, Singer suggested that a passive audience, though unrealistic, was necessary to provide control.

Consistently controlled audience responses were found by Siegman (1976) to have no effect on the facilitation of verbal tasks. The noncontingent nature of these responses may have Inhibited the facilitative nature of the response, as the subjects did not believe the responses of the audience were accurate.

Roberts and Martens (1970) studied motor skill acquisition in relation to four treatment conditions: positive social reinforcement, negative social reinforcement, nonmreinforcement and control. All groups evidenced improved performance, but there was no variance in performance attributable to treatment conditions. Harney and Parker (1972) attributed the failure of social reinforcement to affect complex motor performance to weak reinforcement manipulation. They suggested that the practice of giving reinforcement on a contingency basis after a given number of trials was not sufficient to affect performance. In their study, reinforcement after every trial significantly facilitated motor performance.

Another questionable treatment manipulation has resulted from using too small an audience to facilitate performance. Weiss and Miller (1971) proposed that the intenstey of audience induced drive 
would be Increased as audlence size increased. They found that subjects' performances were worse with audience increments of one to four and significantly better with an audience of five or six. This linear summation effect was supported by McCullough and Landers (1976) who found that arousal increased with the increase in audience size; however, performance was unaffected. Paulus, Judd and Bernstein (1976) found no significant relationship between crowd size and performance of major league baseball players, though effects varied from tean to team.

Wankel (1975) evaluated the interaction effect of audience and social reinforcement conditions upon performance of a stabilometer task. Audience (passive audience, no audience) social reinforcement (positive, negative, no reinforcement) and initial ability level (high, low) were considered. No significant audience, or social relnforcement effects were evident over all trials. In later performance, however, the positive reinforcement group performed at an 1ntermediate level. In the discussion of this research, Wankel questioned the situational factors necessary for producing audience effects on the pertormance of young boys. It was suggested that, perhaps, young boys did not perceive their peers to be sources of evaluative apprehension and that the experimenter may have masked any audience effects. Dominant - Nondominant Responses

Williams (1975) has questioned much of the research which draws conclusions regarding dominant responses. She noted that although some investigations deallng with verbal tasks (Cottrell, Rittle and Wack, 1967; Henchy and Glass, 1968; Hunt and Hillery, 1973; Paulus and Muxdoch, 1971; Zajonc and Sales; 1966) have controlled for the dominance 
of correct of incorrect responses, no researchers using motor triks have established a response hierarchy. Tasks have been subjectively defined according to their difficulty and whether they were being performed in early or late learning stages. Obviously, dominant responses cannot be investigated until their true dominance has been established.

Landers (1975) also found that much research failed to meet the criteria necessary for evaluating the social facilitation phenomenon. He stated that in order to establish necessary task conditions for testing audience effects, the investigator must select a task where both floor and ceiling effects are known. Hunt and Hillery's (1973) use of simple and complex stylus maze tasks was suggested as an appropriate example. The correct response was dominant on the simple task, as its probabilfty of occurrence was .50 or better. Since probability of a correct response on the complex maze was only .25, the incorrect response was determined to be dominant. It was further stated (Landers, 1978) that the rotary pursuit task (Rosenquist, 1972) could be utilized in the same fashion. The dominant, non-dominant responses would be operationally defined as the midpoint of the trial length.

To this date, Iimited effort has been directed toward the consideration of the facilitative response of children in terms of task dominance and the evaluative situation. It is reasonable to suggest that such an examination might provide valuable information regarding the learned drive Interpretation of social facilitation theory. Differential experiences of children in performance before an evaluative audience should allow for clarification of the energizing properties of the evaluative audience as a learned source of drive and provide a 
paradigm for related investigations. Such research may further serve to delineate the cumulative effects of such performance on the child's self-concept and his interest in future performance oriented activities. STATEMENT OF THE PROBLEM

The purposes of this study were to: a) compare performance of 9-year-old boys on a novel rotary pursuit task during an alone situation and a situation in which an evaluative audience is present; b) compare performance of 9-year-old boys on a dominant rotary pursuit task with an evaluative audience and in an alone situation; and c) determine the differential effects of prior performance experience on 9-year-old boys performing a novel or dominant task before an evaluative audience or in an alone situation.

\section{HYPOTHESES}

In light of past social facilftation research, the following hypotheses were examined:

(1) Performance of a novel, complex rotary pursuit task will be Impaired by the presence of an evaluative audience.

(2) Performance of a dominant, complex rotary pursuit task will be facilitated by the presence of an evaluative audience.

(3) Impalrment of performance of a novel, complex rotary pursuit task, due to the presence of an evaluative audience, will occur to a significantly greater extent for subjects with prior experience in performance before an evaluative audience, than for subjects with no prior performance experience. 
OPERATIONAI DEFINITIONS

\section{Social Facilitation}

Refers to any consequences upon individual behavior, specifically, enhanced or impaired performance on a rotary pursuit task, due to the presence of spectators.

Evaluative Audience

A passive audience of four adults, introduced to the subject as having the ability to judge the subject's performance as correct or incorrect.

Dominant Task

Point at which the subject has practiced the complex rotary pursuit task to the extent that the stylus wand is on target at least $60 \%$ of the performance trial time.

Novez Task

A task with which the subject has had no prior experience. In this case a rotary pursuit task, sufficiently complex to insure that the stylus wand is on target $25 \%$ or less of the performance trial time.

\section{Experienced Performer}

Subject who has had at least two seasons of organized sport partictpation involving performance before an audience present, primarily, to observe that performance.

\section{Inexperienced Performer}

Subject who has had no prior experience performing before an audience gathered primarily to observe that performance. 


\section{LIMITATIONS}

(1) Subjects were students as schools assigned to this project by the East Baton Rouge Parish Board of Education and The School District of Greenville County, as well as consenting private schools and, at this level were not randomly selected. Subjects were, however, randomly assigned to treatment conditions.

(2) Findings may be generalized only to subjects who meet the established criteria for prior experience and task dominance. SIGNIFICANCE OF THE STUDY

Humanistic physical education (Hellison, 1973) is unique in its enphasis on the development of a child's positive self concept in regard to his motor abilities. Through these programs, constderable effort has been devoted to providing experiences which engender a feeling of competence regarding one's body and the quality of movement of which one is capable. It is assumed that one who incorporates such perceptions into his value system will pursue physical activity because of the positive feelings one has about oneself when moving.

Such attitudes, however, are modifiable by social experience. Although the child learns much about himself through manipulative exploration and sensory perceptions he is, in fact, information dependent (Jones \& Gerard, 1967), and uti?izes information mediated by others in the social setting. Social approval for a behavior has a positive Informational value and increases the likelihood that the child will. repeat the behavior, while social disapproval has a negative informational value and tends to develop a conditioned avoidance response. 
The performance of many physical tasks is conducted in a social setting. As such, those who perform physical activities, even as children, have innumerable opportunities to receive information regarding their competence or incompetence from evaluative others. In this manner, a physical perfomance which arouses social approval will, in all likelihood, be repeated, while a performance which is not approved will be avoided.

Cottrell's (1968) suggestion that the subject's expectation of evaluation is a learned source of drive infers that the presence of an evaluative audience increases the subject's drive level as a result of past experience with a critical audience or punishment before others. As the number of such occasions increases, observers become, through classical conditioning, stimuli for drive arousal. By considering the differential effects of audience evaluation on subjects with different levels of prior performance experience, this study may delineate the development of the audience-performer relationship.

Thts study represents a concentrated attempt to establish the relationship of a child's prior experience before an evaluative audience. Investigation of the performance of an unlearned and a well-learned task will aid in the refinement of social facilitation theory and determine the combined effects of experience, task dominance and audience situation.

Information should be forthcoming which will clarify the audiencechild interaction and stimulate suggestions for the most positive usage of such a relationship. Such information, combined with children's perceptions of the evaluative situation, should allow for the structure of. a movement program which truly is concerned with the best interest of the child. 
CHAPTER II

METHODS

Subjects

The subjects in this study were 9-year-old boys $(n=80)$ who were students at pubilc and private elementary schools in Baton Rouge, Louisiana and Greenville, South Carolina. The mean age of this sample was $9.5 \pm .4$ years. Selection of the subjects was based on the results of a questionnaire (Appendix A) distributed to parents of 450 male and female students, ages 7,8 , and 9 years. The questionnaire was designed to evaluate the kind and extent of prior performance experiences of children. Parents were requested to record on this questionnaire the activity that the child performed, whether the performance was a solo or group effort, and in how many such performances the child had participated. It was further requested that parents indicate whether the audience observing was formal, whose specific purpose was to observe performance, as opposed to informal, whereby the audience observed performance by coincidence.

Based on the results of the questionnaire, it was determined that the 9-year-old boys met the predetermined criterla for experience and non-experienced performers: non-experienced subjects had no prior experlence performing before a formal audience, while experienced subjects had participated at least two seasons on youth league sport teams which performed before formal audiences.

In addition to the questionnalre, a brief description of the study, 
including a consent form for participation, was distributed to parents of all prospective subjects. Forty right-hand dominant subjects were randomly selected from both the experienced $(n=78)$ and non-experienced $(n=69)$ performers with parental permission to participate.

All subjects were novice to the rotary pursuit task prior to the study. At was further noted that no subject had any physical abnormality which might serve as an impediment to task performance. Rotary Pursuit Task

The motor task utilized in this study was a photoelectric pursuit rotor (Lafayette Instrument Company, Model 2203 ET). An interval timer (Lafayette Instrument Company, Model 54519 A) was utilized to measure time on target for all subjects. The target on this task was set to rotate clockwise in a horizontal plane at $20 \mathrm{rpm}$. The task involved holding a stylus containing a photoelectric cell over the target as it rotated in a circular pattern. The apparatus was placed at waist height for all subjects; target illumination was standardized with a sensitivity control; and speed was set with an rpm meter.

Selection of Dependent Motor Performance Variable

Time-on-target was selected as the dependent variable for this study since the purpose was to evaluate performance quality. This measure reflected accuracy of performance and provided a quantitative ind1cation of the dominance of correct and incorrect responses.

\section{PROCEDURE}

Dominant Response Development

Prior to actual performance under audience conditions, each subject In the dominant response groups participated in sufficient learning 
trials $(\bar{X}=36 \pm 7)$ to establish the correct response as the dominant response, that is to insure that performance was on target at 1 east $60 \%$ of the total trial time. Each child performed 15, 20-second learning trlals, separated by 10-second rest periods, for an unlimited number of days until the performance criterion was met. Also, since subjects reached the criterion on different days, a flve trial review was given to all dominant task subjects one day prior to testing. This insured that forgetting had not lowered the subject's performance level. Novel task groups were not allowed to view or perform the task until actual performance trials were begun.

- Performance Procedures

Novel-task subjects and dominant-task subjects were treated identically with the no audience and evaluatlve audience conditions of performance. The same experimenter and a comparable audience were present for each subject. Environmental conditions were standardized as well. as possible across groups.

Upon entering the experimental area, each subject was directed to a table upon which the rotary pursuit task had been placed. The subject was told that he would be performing the task as a part of an experiment belng conducted by Louisiana State University. The experimenter then explatned and demonstrated the task for two 20-second trials, after which the subject was allowed to question the experimenter until procedures were clearly understood.

Evaluative Audience Condition

The audience of four adults was absent throughout the introductory procedure for all subjects in the evaluative audience condition. Upon 
entering the experimental area, the audience was introduced as a panel of judges, present to observe the subject's performance and evaluate it in comparison to other children. The passive audience stood within view of the subject and at a vantage point from which to clearly observe performance. Each member of the audience was visually attentive to each subject's performance and appeared to make a written evaluation of each performance trial.

Having been introduced to the audience, the subject was instructed to begin performance. Each subject performed five 20-second trials on the rotary pursuit task, with 10 -second rest intervals allowed between each trial. Time-on-target was recorded for each trial.

In order to ascertain each subject's perception of the audience and the effect of the audience on his performance, the subject responded to a questionnaire devised for this purpose (Appendix B). This procedure followed actual performance and preceeded debriefing. No Audience Condition

Following the experimenter's demonstration of the task and the subject's opportunity to clarify instructions, the subject was told that he would be left alone to perform the task. He was told that the experimenter would be working in an area of the room separated by a screen and that he should notify the experimenter when the task was completed.

Subjects in this conditton performed five 20-second trials on the rotary pursuit task, with a 10-second rest interval allowed between trials. Time-on-target was recorded, from the clock counter placed on the experimenter's side of the screen, for each trial. 
Destgn and Data Analysis

A completely randomized design with three factors was utilized for data analysis. The mean of each subject's five time-on-target measures was calculated and a 2 (prior audience experience) $\times 2$ (dominant or novel response) $\times 2$ (audience or no audience) ANOVA was used to determine main effects and interactions among factors.

The null hypotheses tested were:

(1) Performance of a novel complex rotary pursuit task will not be different in the presence of an evaluative audience from that in a no audience condttion for both experienced and non-experienced subjects.

(2) Performance of a dominant complex rotary pursuit task will be no different in the presence of an evaluative audience than in a no audience condition for both experienced and non-experienced subjects.

(3) There will be no difference in performance of the novel and complex rotary pursuit tasks, due to the presence of an evaluative audience, for subjects with prior performance experience before an evaluative audience and subjects with no prior performance experience. 


\section{CHAPTER III}

\section{RESULTS}

\section{Performance Experience Questionnaire}

Performance experience questionnaires were distributed to 450 parents of male and female students ages $7(\mathrm{~N}=120), 8(\mathrm{~N}=135)$, and 9 $(\mathrm{N}=195)$ years. Of the 247 returned questionnatres, 64 (38 male, 26 female) 7-year-olds, 89 (49 male, 40 female) 8-year-olds and 153 (96 inale, 57 female) 9-year-olds were represented.

Responses from parents of 7-year-old boys indicated that seven, or $14 \%$, of those responding had at least two seasons performance experience in youth sport activities, while $76 \%$ had no performance experience before a formal audience. No 7-year-old girls were reported as having participated in youth sport activities. Twelve or $24 \%$ of the 8 -year-old boys were reported to have participated at least two seasons, on youth sport teams, and $65 \%$ were reported as having no experience performing before a formal audience. Only six, or 15\%, of the 8-year-old females were reported as having two seasons of participation on youth league teams. Parents of 9-year-old boys returning the questionnaire indicated that 37 , or $39 \%$, had participated in youth sport activities for at least two seasons. Forty-one, or $43 \%$, of these 9-year-old males had no experience performing before a formal audience. Eleven, $19 \%$, of the 9-year-old females were indicated as having two seasons of youth sport participation.

Based on the results of the returned questionnaires, it was determined that the sample of $9 \rightarrow y e a r-o l d$ boys best met the predetermined 
criteria for experienced and non-expertenced performers: non-experienced subjects had no prior experience performing before a formal audience, while experienced subjects had participated at least two seasons on youth league sport teams which performed before formal. audiences.

Dominant Response Development

To assure that experienced and non-experienced subjects were no different from each other in regard to hand-eye coordination, a $t$-test was utilized. This comparison of experienced and non-experienced performers, on a novel task, in a no audience situation, evidenced no significant differences $t(18)=.21, \underline{p}>.05$ in baseline performance on the rotary pursuit task.

The number of learning trials necessary to reach the established criterion was also evaluated for differences between experienced and non-experienced performers. The mean number of learning trials required for experienced subjects to reach criterion was $34 \pm 5$, while nonexperienced subjects required $37 \pm 6$ trials, $t \underline{t}(38)=1.72, \underline{p}>.05$. Mean scores of the five review trials indicated that experienced performers improved their mean score of time-on-target $1.7 \pm .6$ seconds over their mean of their final five learning trials; non-experienced performers improved their mean time-on-target score $1.5 \pm .7$ seconds in the trial review session, as compared to their last five performance trials, $t(38)=.97, \underline{p}>.05$. Consequent1y, experienced subjects did not have an advantage from the standpoint of motor learning capabilities on this task over non-experienced performers. 
Statistical Analysis

The 2 (experience) $\times 2$ (task dominance) $\times 2$ (audience) ANOVA presented In Table 1, yielded a significant difference between the means for the novel task and the learned task $\mathrm{F}(1,72)=744.19, \mathrm{P}<.0001$. The differ-

Table I. 2(Experience) $\times 2$ (Task Dominance) $\times 2$ (Audience) ANOVA

\begin{tabular}{lrrrr}
\hline Source & df & \multicolumn{1}{c}{ SS } & \multicolumn{1}{c}{ MS } & \multicolumn{1}{c}{ E } \\
\hline Task & 1 & 1311.50 & 1311.50 & $744.19^{* *}$ \\
Experience & 1 & .06 & .06 & .04 \\
Task x Experience & 1 & 3.14 & 3.14 & 1.78 \\
Audience & 1 & 5.55 & 5.55 & 3.15 \\
Task x Audience & 1 & 52.57 & 52.57 & $29.83^{* *}$ \\
Experience x Audience & 1 & .01 & .01 & .01 \\
Task x Experience x Audience & 1 & 1.52 & 1.52 & .87 \\
Error & 72 & 126.89 & 1.76 & \\
\hline
\end{tabular}

* $\underline{\mathrm{P}}<.05 \quad * * \underline{\mathrm{P}}<.01$

ence between these mean scores, as indicated in Table 2, demonstrates that regardless of prior performance experience and current audience conditions, subjects who had learned the task to criterion performed consistently better than did those who performed this task as a novel experience.

Table 2. Mean Scores of Novel and Learned Task Groups

\begin{tabular}{lccc}
\hline Task & $\underline{\underline{n}}$ & $\underline{\text { M score }(\text { sec.) }}$ & $\underline{\text { S.D. }}$ \\
\hline Nove1 & 40 & 3.96 & 1.78 \\
Learned & 40 & 12.05 & 3.20 \\
\hline
\end{tabular}

No other significant main effects were evident from this analysis, however, the audience main effect was shown to approach significance 
$E(1,72)=3.15, \underline{\mathrm{P}}<.08$.

A significant task $x$ audience interaction, $\underline{F}(1,72)=29.83$, $\mathrm{p}<.0001$, was also evident. The difference between the mean scores of novel task subjects with and without an audience was less than the difference between the mean scores of learned task subjects with and without an audience. The Newman-Kuels Test analysis shown in Table 3 demonstrates that in the novel task condition, subjects performing before an evaluative audience experienced significantly higher scores than those in the no audience condition, while subjects who had learned the task to criterion demonstrated stgnificantly lower scores in the evaluative audience than in the no audience condition. These findings are more clearly depicted in Figure 1 .

Table 3. Newman-Kuels Test for Task x Audience Interaction

\begin{tabular}{lccc}
\hline Group & 2 & \multicolumn{3}{c}{ Comparison } & 4 \\
\hline 1. Novel Task/No Audience & $9.72^{*}$ & $7.57^{*}$ & 1.09 \\
2. Dominant Task/No Audience & - & $2.15^{*}$ & $8.63^{*}$ \\
3. Dominant Task/Audience & & - & $6.48^{*}$ \\
4. Novel Task/Audience & & & - \\
\hline$\underline{\mathrm{p}}<.05$ & & &
\end{tabular}

Interactions for task $\mathrm{x}$ experience, experience $\mathrm{x}$ audience and task $\mathrm{x}$ experlence $\mathrm{x}$ audience were nonsignificant. These data, along with that for nonsignificant main effects, have been placed in Appendix C. Causal Perception Questionnaire

The responses of subjects to the Causal Perception Questionnaire 


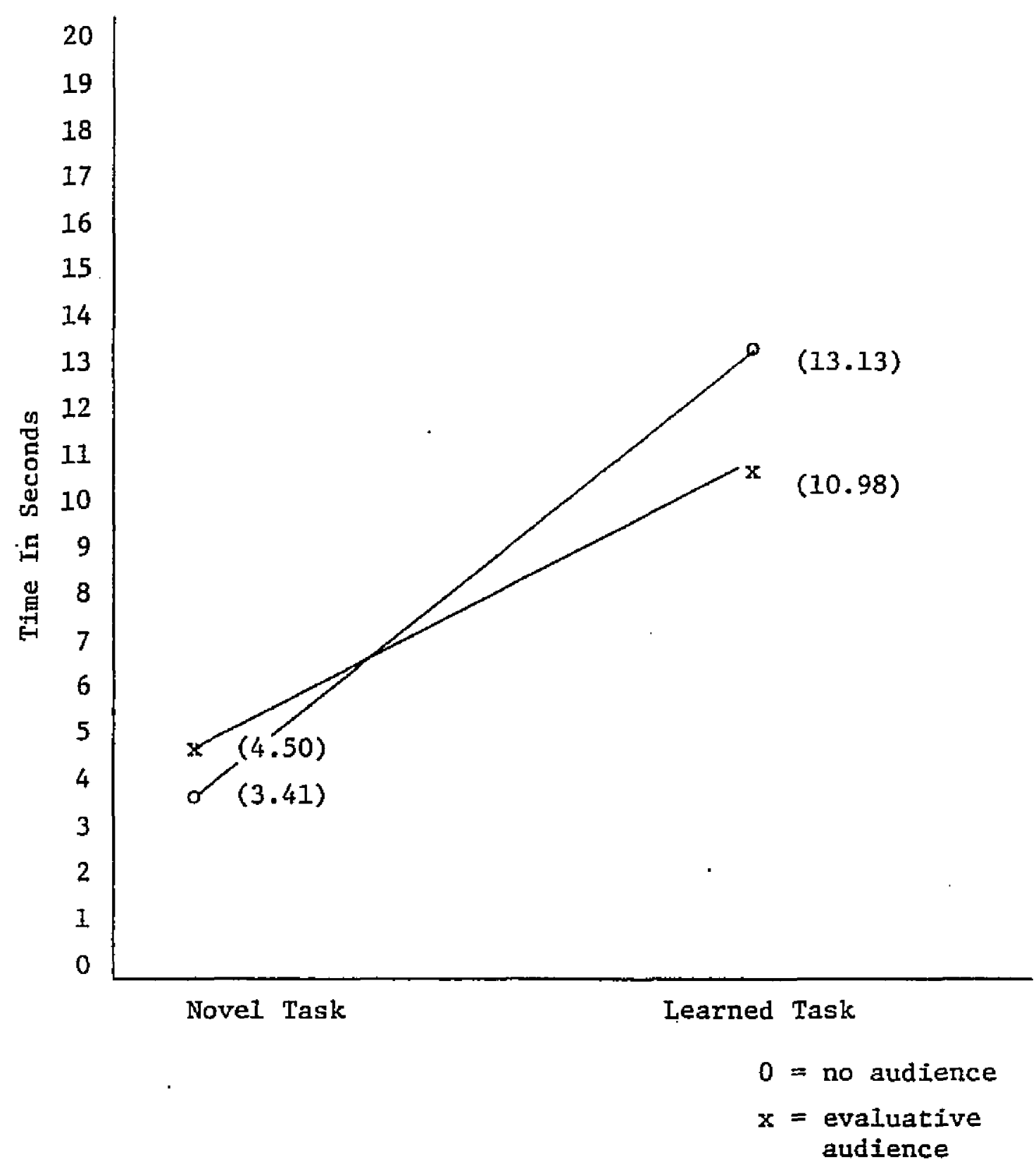

Figure 1. The effect of task $x$ audience interaction on mean rotary pursuit scores. 
(Appendix D) indicate only one obvious difference between novel and dominant task subjects in the evaluative situation. Novel task subjects Indicated that the audience made then feel good (55\%), bad (5\%), no different (35\%) and nervous (5\%). Dominant task subjects, on the other hand, indicated that the audience made them feel good (55\%), no different (19\%) and nervous (35\%).

Questionnaire response differences observed between experienced and non-experfenced subjects indicated that the non-experienced subjects perceived the audience as slightly more positive than did the experienced subjects. Only $40 \%$ of the experienced subjects thought they played better when the audience observed their performance, while $60 \%$ of the non-experienced subjects expressed that perception. No non-experienced subjects perceived their performance to be worse due to the evaluative audience, while $15 \%$ of the experienced subjects expressed this view. Non-experienced subjects indlcated a desire to repeat this task performance before an audience to a greater extent (95\%) than did experienced subjects (70\%), however, both groups indicated a similar interest (95\%) in performing another task of their chotce before the audience. Other differences between these subjects were minimal. 
CHAPTER IV

DISCUSSION

Cottrell's (1968) modification of Zajonc's (1965) social facilitation theory served as the basis for the research hypotheses that were tested in this study. According to Cottrell, a subject's expectation of evaluation is a learned source of drive, an aversive stimulus conditioned by past expexiences with audiences. This stimulus, according to Cottrell (1968), increases the subject's drive level in subsequent performance experiences before evaluative audiences, facilitating performance of a well-learned task and hindering performance of a novel task.

This relationship between a child's prior experience before an evaluative audience and the quality of his present performance was not supported by the findings of this study. Rather, it was found that the performance of subjects with no prior experience before an audience was no different under current evaluative audience or no audience conditions than the performance of subjects who had previously performed before attentive audiences.

Failure to support Cottrell's theory in regard to expexience based differences may be somewhat related to the responses of. subjects in the evaluative audience condition to the causal perception questionnaire. These responses (Appendix D) indicate only minute differences between the responses of experienced and non-expertenced subjects to the evaluative audience condition. Both groups indicated that they enfoyed their performance on the pursult rotor task, but neither group believed that the audience influenced their performance on that task. The groups also 
responded similarly in noting their perception of the audience's evaluative ability. Both groups perceived the audience to be accurate in Its evaluation of their performance and believed, further, that they performed the task as well as they thought the audlence believed they did. Again, there was no difference in response when both groups indicated that they would like to have an audience observe a future performance on the pursuit rotor task or the performance of an activity of their choice.

These responses clearly indicate that subjects' prior performance experiences resulted in no observable differences in thetr responses to the evaluative situation, at least of the type employed in this study. Furthermore, no trace of an aversive response to the audience was evident. For this reason, it is understandable that subjects' drive levels were not affected by the expertmental factor and that no significant differences were observed.

The differences observed in the task $\mathrm{x}$ audience interaction also fails to support Cottrell's (1968) theory; in fact, just the opposite was observed. According to Cottrell, the presence of an evaluative audience should facilitate performance of a well-learned task while hindering performance of a novel task. This study indicates that subjects in the novel task condition performed better in the presence of an evaluative audience than in a no audience condition, while subjects who had learned the task to criterion performed better in the no audience than evaluative audience condttion. This response may serve as an indication that subjects who learned the task in a no audience situation would perform the task better under the condittons in which initial 
learning took place. As no learning trials were conducted in the presence of an audience, other than the experimenter, it is impossible to fully evaluate this premise.

Again, a consideration of causal perception questionnaire responses may afd in the explanation of these findings. Perceptions were comparable between novel and learned group subjects on most questions. Both novel and learned task subjects enjoyed being observed while performing the pursuit rotor task; both groups perceived the audience to be accurate in its evaluation of their performance; and neither believed that the audience influenced their performance. It was further indicated that both groups would like to be observed when they performed the pursuit rotor task again, as well as when performing a game of their choice.

A major difference, however, was evident between these groups' perceptions of how the audience made them feel. Novel task subjects responded that the audience made them feel good $(55 \%)$, bad (5\%), no different (35\%) and nervous (5\%). Learned task subjects indicated that the audience made them feel good (55\%), no different (10\%) and nervous (35\%). The nervousness indicated here by a larger percentage of learned task subjects may serve as a possible source of the variability between the performances of the novel task, no audience and evaluative audience groups. According to drive theory (Beck, 1978), however, which serves as the basis for Zajonc's (1965) and CottrelI's (1968) social facilitation theories, anxiety should increase drive and facilitate the dominant respons. As performance of the learned task was hindered by the presence of the evaluative audience, and performance of 
the novel task facilitated, this theory is not a functional explanation of the trend noted in the direction of the performance scores.

Since all subjects in the learned task group practiced the task until they met a predetermined performance criterion and, as ali subjects' performance quality was reevaluated prior to actual performance in the evaluative audience situation, it is not plausible that the observed difference was a result of differential task dominance of forgetting. The consistency of task dominance is substantiated in the observed significance of the difference between the mean scores of novel and learned task groups.

The failure of Cottrell's theory to explain these findings suggests that other factors may have influenced performance. Consideration of a distraction - conflict variable (Baron, Moore \& Sanders, 1978; Sanders \& Baron, 1975) may provide some clarification of findings. It has been hypothestzed that subjects in social facilitation studies are more distracted under audience conditions than when performing alone. Attentional conflict tncreases drive when subjects are motivated to work diligently on a task, as perhaps was the case in the novel task learning situation. When motivation is decreased, as when the subject has practiced the task for a considerable period of time, drive may be decreased. Thus, consideration of the distraction-conflict theory, which is probably the most current in social facllitation theory, seems to be the most functional explanation of the results of this study.

The failure of this research project to support CottrelI's (1968) social facilitation theory represents a positive rather than a negative phenomenon. The absence of an aversive response to a controlled, 
evaluative audience by children performing in the youth sport setting, indicates that childhood sport activities can be conducted in a more constructive atmosphere than depicted by many youth sport critics. It further indicates that the 9-year-old boys who participated in this study have suffered no lasting effects of negative audience responses in their youth sport experiences, at least as far as may be transferred to current experimental conditions.

The overall acceptance of audience observation during performances subsequent to youth sport participation indicates a utilization of information which has a positive value and may, in turn, foster a feeling of competence regarding the quality of movement of which these subjects are capable. Certainly such a perception would increase the 1ikelihood that these children will pursue activities involving audiences, i.e. sport activities, in the future.

The age of subjects may be of primary importance with regard to the specific results of this study. The humanistic philosophy of movement and youth sport reform have been in effect for the duration of a 9-year-old's yours of sport participation. This concentrated effort toward providing the most constructive movement program possible for all children may already be reaping the fruits of its labor.

\section{CONCLUSIONS}

Several general conclusions can be drawn from the results of the present study:

1. Experience performing before an evaluative audience is not sufficient, in teself, to condition an aversive response observable in future performance before an evaluative audience. 
2. Cottrell's (1968) social facilftation theory does not provide a fully operational model of the social facilitation phenomenon, at least with regard to the age and experience level of the subjects in this study. The distraction - conflict variable must be considered in order to clarify variability among individuals.

\section{RECOMMENDATIONS}

The results of this study indicate that additional research is imperative to define the role of experience in social facilitation theory. Consideration of the distraction - conflict phenomenon is also suggested. An evaluation of the responses of a variety of age groups to performance before an evaluative audience may indicate the extent to which the absence of an aversive response by 9-year-old subjects is a function of youth sport revision and the humanistic philosophy of movement. 
Ha11, E. G. The interrelationship of locus of control, sex, competition and coaction during motor skill performance. Unpublished Doctoral Dissertation, University of Virginia, 1977.

Landers, D. M. Personal Communication. September, 1978.

Landers, D. M. Personal Communication. March, 1979.

Rosenquist, H. S. Social facilitation in rotary pursuit tracking. Unpublished manuscript, University of Akron, 1972.

Williams, J. M. Effects of evaluative and nonevaluative coactors upon male and female performance of simple and complex motor tasks.

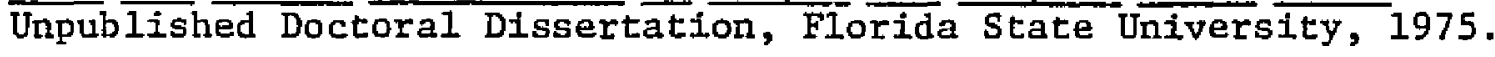




\section{REFERENCES}

Abel, T. M. The influence of social factlitation on motor performance at different levels of intelligence. American Journal of Psychology, 1938, $\underline{51}, 379-89$.

AlIport, G. H. The influence of the group upon association and thought. Journal of Experimental Psychology, 1920, 3, 159-82.

AlIport, G. H. Soclal psychology. Boston, Mass.: Houghton-Mifflin, 1924.

Baron, R. S., Moore, D. \& Sanders, G. S. Distraction as a source of drive in social facilttation research. Journal of Personality and Social Psychology, 1978, 36, 816-824.

Beck, R. C. Motivation: Theories and principles. Englewood Cliffs, N. J.: Prentice-Ha11, Inc., 1978 .

Bergum, B. O. \& Lehr, D. J. Vigilance performance as a function of paired monitoring. Journal of Applied Psychology, 1962, 46, $341-43$.

Bergum, B. O. \& Lehr, D. J. Effects of authoritarianism on vigilance performance. Journal of Applied Psychology, 1963, 47, 74-77.

Bird, A. M. Effects of social facilitation upon females' performance of two psychomotor tasks. Research Quarterly, 1973, 44, 322-24.

Burri, C. The influence of an audience upon recall. Journal of Educational Psychology, 1931, 22, 683-90.

Burwitz, L. \& Newell, K. M. The effect of the mere presence of coactors on Iearning a motor skill. Journal of Motor Behavior, 1972, 4 , $71-126$.

Carment, D. W. Rate of simple motor responding as a function of coaction, competition and sex of the participants. Psychonomic Science, $1970,19,342-43$. (a)

Carment, D. W. Rate of simple motor responding as a function of differential outcomes and the actual and implied presence of a coactor. Psychonomic Science, 1970, 20, 115-16. 
Carment, D. W. \& Latchford, M. Rate of simple motor responding as function of coaction, sex of the participants, and the presence or absence of the experimenter. Psychonomic Science, 1970, 20, 253-54.

Chevrette, J. M. The effects of peer observation on selected tests of phystcal performance. Journal of Applied Psychology, 1968, $\underline{8}$, 113-19.

Cottrell, N. B. Performance in the presence of other human beings: Mere presence, audience and iffiliation effects. In E. C. Simnel, R. A. Hoppe, \& G. A. Milton, (Eds.), Social facilitation and imitative behavior. Boston: Allyn \& Bacon, 1968 .

CottrelI, N. B., Rittle, R. H. \& Wack, D. L. The presence of an audience and list type (competitional or non-competitional) as joint determinants of performance in paired-associate learning. Journal of Personality, 1967, 35, 425-34.

Cottre11, N. B., Rittle, R. H., Sekerak, G. H. \& Wack, D. L. Social. factlitation of dominant responses by the presence of an audience and the mere presence of others. Iournal of Personality and Social Psychology, 1968, 9, 245-50.

Cox, F. N. Some effects of test anxiety and presence or absence of other persons on boys' performance on a repetitive motor task. Journal of Experimental Child Psychology, 1966, $3,100-12$.

Criddle, W. D. The physical presence of other individuals as a factor in social facilitation. Psychonomic Science, 1971, 22, 229-30.

Dashiell, J. F. An experimental analysis of some group effects. Journal of Abnormal Social Psychology, 1930, 25, 190-99.

Ganzer, V. J. Effects of audience presence and test anxiety on learning and retention in a serial learning situation. Journal of Personality and Social Psychology, 1968, 8, 194-99.

Gates, G. S. The effect of an audience upon performance. Journal of Abnorma1 Psychology, 1924, 18, 334-42.

Haas, J. \& Roberts, G. C. Effect of evaluative others upon learning and performance of a complex task. Journal of Motor Behavior, $1975, \underline{7}, 81-90$.

Harney, D. M. \& Parker, R. Effects of social reinforcement, subject sex and experimenter sex on children's motor performance. Research Quarterly, 1972, 43, 187-96. 
Harnett, J. J., Gottleib, J. \& Hayes, R. L. Social facilitation theory and experimenter attractiveness. Journal of Social Psychology, $1976, \underline{99}, 293-94$.

Hellison, D. Humanistic physical education, Englewood Cliffs, N. J.: Prentice-Hal1, Inc., 1973.

Henchy, T. P. \& Glass, D. C. Evaluation apprehension and the social facilitation of dominant and subordinate responses. Journal of Personality and Social Psychology, 1968, 10, 446-54.

Hunt, P. J. \& Hillery, J. M. Social facilitation in a coaction setting: An examination of the effects over learning trials. Journal of Experimental Social. Psychology, 1973, 9, 563-71.

Jones, E. E. \& Gerard, H. B. Foundations of social psychology. New York, N. Y.: John Wiley \& Sons, Inc., 1967 .

Kennedy, W. A. \& Willcutt, H. C. Praise and blame as incentives. Psychological Bulletin, 1964, 62, 323-32.

Klinger, E. Feedback effects and social facllitation of vigilance performance: Mere coaction versus potential evaluation. Psychonomic Sciences, 1969, 12, 252-60.

Laird, D. A. Changes in motor control and individual variations under the influence of razzing. Journal of Experimental Psychology, $1923,6,236$.

Landers, D. M. Social facilitation and human performance: A review of contemporary and past research. Psychology of Sport and Motor Behavior, 1975, 2, 195-208.

Livingston, M. V., Landers, D. M. \& Dorrance, P. B. Comparison of coacting individuals' motor performance for varying combinations of initial ability. Research QuarterIy, 1974, 45, 310-17.

Lombardo, J. P. \& Catalano, J. F. The effect of failure and the nature of the audience on performance of a complex motor task. Journal of Motor Behavior, 1975, $7,29-35$.

Martens, R. Social reinforcement effects on preschool children's motor performance. Perceptual and Motor Skills, 1970, 31, 787-92.

Martens, R. Effect of an audience on learning and performance of a complex motor skill. Journal of Personality and Social Psychology, $1969,12,252-60$ 
Martens, R. Effect on performance of learning a complex motor task in the presence of spectators. Research Quarterly, 1969, 40, 317-23.

(b)

Martens, R. \& Landers, D. M. Coaction effects on muscular endurance. Research Quarter1y, 1969, 40, 733-37.

Martens, R. \& Landers, D. M. Evaluation potential as a determinant of coaction effects. Journal of Experimental Soctal Psychology, 1972, 8, 347-59.

McCullough, P. D. \& Landers; D. M. Size of Audience and social facilitation. Perceptual and Motor Skills, 1976, 42, 1067-70.

Meyer, W. J. \& Offerbach, S. I. Effectiveriess of reward and punishment as a function of task complexity. Journal of Comparative and Physiological Psychology, 1962, 55, 532-34.

Missiuro, W. The development of reflex activity in children. In E. JokI \& E. Simons (Eds.) International Research in Sport and Physical Education, Springfield, I11.: Charles C. Thomas, 1964, $\overline{372-83 .}$

Moore, H. T. Laboratory tests of anger, fear and sex interest. American Journal of Psychology, 1917, ㄱ, 280-91.

Paulus, P. B., Judd, B. B. \& Bernstein, R. H. Social facilitation and sports, Proceedings of the North American Society for the Psycho1ogy of sport and Physical Activity, 1976, $2,2-8$.

Paulus, P. B. \& Cornelius, W. L. An analysis of gynmastic performance under conditions of practice and spectator observation.

Paulus, P. B. \& Murdoch, P. Anticipated evaluation and audience presence in the enhancement of dominant responses. Journal of Experimental Psychology, 1971, I, 280-91.

Pessin, J. The compaxative effects of social and mechanical stimulation on memorizing. American Journal of Psychology, 1933, 45, 263-70.

Pessin, J. \& Husband, R. W. Effects of soctal stimulation on human maze learnfing. Journal of Abnormal and Social Psychology, 1933, 28,

Roberts G. C. Effect of achievement motivation and social reinforcement on performance of a motor task. Journal of Motor Behavior, 1972 , 4, $37-46$.

Roberts, G. C. \& Martens, R. Social reinforcement and complex motor performance. Research Quarterly, 1970, 41, 175-81. 
Sanders, G. S. \& Baron, R. S. The motivating effects of distraction on task performance. Journal of Personality and Social Psychology, $1975, \underline{32}, 956-63$.

Sasfy, J. \& Okun, M. Form of evaluation and audience expertness as joint determinants of audience effects. Journal of Experimental Social Psychology, 1974, 10, 461-67.

Siegman, A. W. Do noncontingent interview mnhmms factlitate interviewee productivity? Journal of Consulting and Clinical Psychology, $1976, \underline{44}, 171-82$.

Singer, R. N. Effect of spectators on athletes and non-athletes performing a gross motor task. Research Quarterly, 1965, 35, 473-82.

Singer, R. N. Effects of an audience on performance of a motor task. Journal of Motor Behavior, 1970, 2, 88-95.

Smol1, F. L. \& Denotter, P. Intraindividual variability in development of accuracy of motor performance. Journal of Motor Behaviox, $1976,8,195-201$.

Spence, J. T. \& Spence, K. W. The motivational components of manifest anxiety: Drive and drive stimuli. In C. D. Spielberger (Ed.), Anxiety and Behavior. New York: Academic Press, 1966.

Travis, L. E. The effect of a small audience upon eye-hand coordination. Journal of Abnormal Social Psychology, 1925, 20, 142-46.

Triplett, N. The dynamogenic factors in pace-making and competition. American Journal of Psychology, 1897, 9, 507-33.

Wankel, L. M. The effects of social reinforcement and audience presence upon the motor performance of boys with different levels of initial ability. Journal of Motor Behavior, 1975, 7, 207-16.

Wanke1, L. M. Competition in motor performance: An experimental analysis of motivational components. Journal of Experimental Social Psychology, 1972, 8, 427-37.

Weiss, R. F. \& Miller, F. G. The drlve theory of social facilitation. Psychological Review, 1971, 78, 44-57.

Zajonc, R. B. Social facilitation, Science, 1965, 149, 269-74.

Zajonc, R. B. \& Sales, S. M. Social facilftation of dominant and subordinate responses. Journal of Experimental Social Psychology, 1966,2 , $160-68$. 
Appendix A 
LOUISI AN A STATE UNIVERSITY and AgRICULTURAL and MECHANical COLlege BATON ROUGE - LOUISIANA - 70803

Dear Parent:

A research study to determine the extent and kind of children's performance expertences before audiences is currently being done through the Department of Health, Physical and Recreation Education at Loulsiana State University. We are interegted in determining how children's performance experiences differ across age and sex. For this reason, we are requesting that you complete the attached questionnaire, noting your chlld's performance. experiences and his/her age.

After determining the results of this survey, we would like to evaluate some chlldren's performances before an audience or in a no-audience situation. Approximately 80 children will be asked to perform a rotary pursult "tracking" task, which requires simply that the child, using a stylus wand, maintain contact with a target, moving In a clrcular pattern. Some chlldren will practice the task and become skilled at it before performance. Others w 111 not practice. Children particlpating in this phase of the project will remain completely anonymous and will be given a full explanation of the study after its completion.

If your child has permission to particlpate in the performance phase of this study, please sign the permission portion of the attached form. If you prefer that your child not participate, we would still appreclate your cooperation in completing the informational survey. I will be happy to answer any questions you might have regarding this profect.

Thank you for your cooperation.

Sincerely yours,

N. Lucinda Hollifield

Graduate Assistant

388-2036 


\section{Performance Experience Questionnaire}

Please check the appropriate statement regarding your child's experience as a performer. The term formal audience is used to denote an audience which was present specifically to observe and attended directly to said performance. An informal audience refers to an audience which coincidenta1ly was present when the performance took place and may or may not have attended directly to the performance.

$$
\text { child's age }
$$

check here

No experience in performance before a formal audience.

Experience in group performance before a formal audience.

Complete below.

\section{ACTIVITY}

Dance Recital

Music Recital

Scout Programs

Camp Programs

PTA Programs

School Class Programs

Church Programs

Family Programs

Sport Programs*

NUMBER OF SPORTS PER YEAR
AVERAGE NUMBER

PERFORMANCE PER FORMANCES PER YEAR

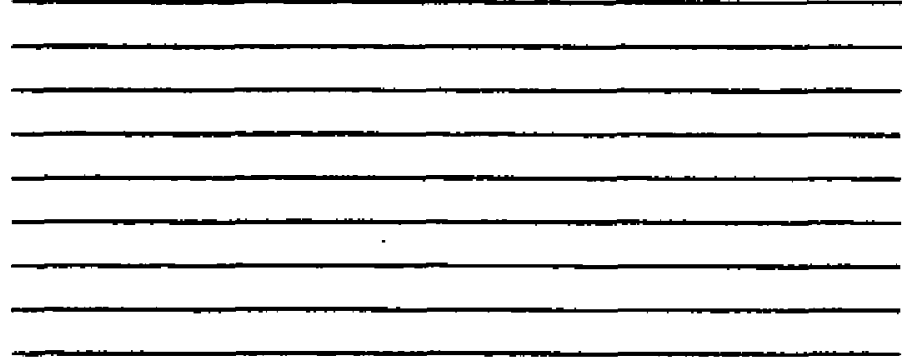

AVERAGE NUMBER OF GAMES PER YEAR

church league school league recreation league

Other

*indicate sports played each 
check here

Experience in solo performance before a formal audience.

Complete below

$\underline{\text { ACTIVITY }}$

Dance Recital

Music Recital

Scout Programs

Camp Programs

PTA Programs

School Class Programs

Church Programs

Family Programs

Sport Programs*

*indicate sports played each year

Experience in group performance before an informal audience.*

NATURE OF

AUDIENCE

Family

Familiar Adults

Unfamiliar Adults

Teachers

Schoolmates

Neighborhood Friends

Unfamillar Children

Other
YEARS OF PERFORMANCE PER

NUMBER OF SPORTS PER YEAR $\underline{\text { GAMES }}$ PER YEAR church league school league recreation league

Other 
check here

Experience in solo performance before an informal audience.*

NATURE OF

ITATURE OF YEARS OF AVERAGE NUMBER OF AUDIENCE PERFORMANCE PERFORMANCE PERFORMANCES PER YEAR

Family

Familiar Adults Unfamiliar Adults

Teachers

Schoolmates

Neighborhood Friends

Unfamiliar Children

Other

*Please elaborate regarding any sport performances. 
DATE

*TO BE RETAINED BY THE INVESTIGATOR

\section{EXPERIMENT SIGN-UP FORM}

My signature, on this sheet, by which I give permission for my child to participate in the experiment conducted by $\mathrm{N}$. Lucinda Hollifield indicates that I understand that all subjects in the project are volunteers, that my child can withdraw at any time from the experiment, that I have been or will be informed as to the nature of the expertment, that the data my child provides will be anonymous and his/her identity will not be revealed without my permission, and that his/her performance in this experiment may be used for additional approved projects. Finally, my child and $I$ shall be given an opportunity to ask questions prior to the start of the experimentation and after his/her participation is complete. 
Appendix B 
Causal Perception Questionnaire

1. Did you enjoy playing the tracking game?

Yes No

2. Did you enjoy having people watch you while you played the game?

Yes No

3. How did the audience make you fee1?

Good Bad No Different Other

4. Did the audience make a difference in how well you played the Game?

Yes No

a. Did you play better because there were people watching you? Yes No

b. Did you play worse because there were people watching you? Yes No

5. Did the audience think that you played the game well?

Yes No

a. Did you play the game as well. as they thought?

Yes No

b. Did you play the game better than they thought?

Yes No

c. Did you play the game worse than they thought?

Yes No 
6. Would you like to play the game again?

Yes No

7. Would you like to have people watch you when you play the game again?

Yes No

8. Would you like to have people watch you when the play another game that you like?

Yes No

a. What game is it?

b. Why would you choose that game? 
Appendix C 
ANALYSIS OF VARIANCE MEANS

MAIN EFFECTS

\begin{tabular}{lcc} 
Task & $\mathbb{N}$ & $\underline{M}$ Score (sec.) \\
\hline Novel & 40 & 3.96 \\
Learned & 40 & 12.05 \\
\hline
\end{tabular}

\begin{tabular}{lcc} 
Experience & N & M Score (sec.) \\
\hline Nonexperienced & 40 & 8.03 \\
Experienced & 40 & 7.98 \\
\hline
\end{tabular}

\begin{tabular}{|c|c|c|}
\hline Audience & $\mathbf{N}$ & $\bar{x}$ score (sec.) \\
\hline No Audience & 40 & 8.27 \\
\hline Audience & 40 & 7.74 \\
\hline
\end{tabular}




\section{ANALYSIS OF VARIANCE MEANS}

TWO-WAY INTERACTIONS

\begin{tabular}{|c|c|c|c|}
\hline Task $\quad \mathbf{x}$ & Experience & $\mathrm{N}$ & M Score (sec.) \\
\hline Nove1 & Nonexperienced & 20 & 3.79 \\
\hline Novel & Experienced & 20 & 4.13 \\
\hline Learned & Nonexpertenced & 20 & 12.28 \\
\hline Learned & Experienced & 20 & $\mathrm{I} .1 .83$ \\
\hline Task $\cdot \mathbf{x}$ & Audience & $\mathrm{N}$ & M Score (sec.) \\
\hline Novel & No & 20 & 3.41 \\
\hline Nove1. & Yes & 20 & 4.50 \\
\hline Learned & No & 20 & 13.13 \\
\hline Learned & Yes & 20 & 10.97 \\
\hline Experience $\mathrm{x}$ & Audience & $\mathrm{N}$ & M Score $(\mathrm{sec})$ \\
\hline Nonexperienced & No & 20 & 8.28 \\
\hline Nonexperienced & Yes & 20 & 7.78 \\
\hline Experienced & No & 20 & 8.25 \\
\hline Experienced & Yes & 20 & 7.78 \\
\hline
\end{tabular}


ANALYSIS OF VARIANCE MEANS

THREE-WAY INTERACTIONS

\begin{tabular}{|c|c|c|c|c|c|c|}
\hline Task & $\mathbf{x}$ & Experience & $x$ & Audience & $\mathbf{N}$ & $\underline{M}$ Score sec.) \\
\hline Novel & & Nonexperienced & & No & 10 & 3.37 \\
\hline Novel & & Nonexperienced & & Yes & 10 & 4.42 \\
\hline Novel & & Experienced & & No & 10 & 3.45 \\
\hline Novel & & Experienced & & Yes & 10 & 4.80 \\
\hline Learned & & Nonexperienced & & No & 10 & 13.20 \\
\hline Learned & & Nonexperienced & & Yes & 10 & 11.35 \\
\hline Learned & & Experienced & & No & 10 & 13.05 \\
\hline Learned & & Experienced & & Yes & 10 & 10.60 \\
\hline
\end{tabular}


APPENDIX D 
Responses of Nonexperienced

Novel Task Subjects

Causal Perception Questionnaire

1. Did you enjoy playing the tracking game? Yes No

2. Did you enjoy having people watch you while you played the game?

Yes No

100

3. How did the audlence make you feel? Good Bad No Different

Other Nervous

4. Did the audience make a difference in how well you played the game?

Yes No

28

a. Did you play better because there were people watching you?

$\begin{array}{rr}\text { Yes } & \text { No } \\ 6 & 4\end{array}$

b. Did you play worse because there were people watching you?

Yes No

$0 \quad I 0$

5. Did the audience think that you played the game well? Yes No

a. Did you play the' game as well as they thought? Yes 9

b. Did you play the game better than they thought? Yes 1 No

c. Did you play the game worse than they thought? Yes No

6. Would you like to play the game again? Yes No

19

7. Would you like to have people watch you when you play the game again.

Yes No

$10 \quad 0$

8. Would you like to have people watch you when you play another game that you like? Yes No

a. What game is it?

b. Why would you choose that game?

* number of responses $n=10$ 
Responses of Nonexperienced

Learned Task Subjects

Causal Perception Questionnaire

1. Did you enjoy playing the tracking game? Yes No

$7 * 3$

2. Did you enjoy having people watch you while you played the game?

Yes No

73

3. How did the audience make you feel? Good Bad No Different Other Nervous

4. Did the audience make a difference in how well you played the game?

Yes No

28

a. Did you play better because there were people watching you?

Yes No

64

b. Did you play worse because there were people watching you?

Yes No

010

5. Did the audience think that you played the game wel1? Yes No

a. Did you play the game as well as they thought? Yes ${ }^{8}$ No

b. Did you play the game better than they thought? Yes No

c. Did you play the game worse than they thought? Yes ${ }^{3}$ No

6. Would you like to play the game again? Yes No

7. Would you like to have people watch you when you play the game again?

Yes No

91

8. Would you like to have people watch you when you play another game

that you like? Yes No

a. What game is it?

b. Why would you choose that game?

* number of responses

$\mathfrak{n}=10$ 
Total Responses

of Nonexperienced Subjects

Causal Perception Questionnaire

1. Did you enjoy playing the tracking game? Yes No

2. Did you enjoy having people watch you while you played the game?

Yes No

155

3. How did the audience make you feel? Good Bad No Different Other Nervous

4. Did the audience make a difference in how well you played the game?

Yes No

$4 \quad 16$

a. Did you play better because there were people watching you?

Yes No

128

b. Did you play worse because there were people watching you?

Yes No

020

5. Did the audience think that you played the game well? Yes No

a. Did you play the game as well as they thought? Yes No

b. Did you play the game better than they thought? $\begin{array}{lll}16 & 4 \\ \text { Yes } & \text { No }\end{array}$

c. Did you play the game worse than they thought? Yes No

6. Would you like to play the game again? Yes No

182

7. Would you like to have people watch you when you play the game again?

Yes No

191

8. Would you like to have people watch you when you play another game that you Iike? Yes No

a. What game is it?

b. Why would you choose that game?

* number of responses

$n=20$ 
Responses of Experienced

Learned Task Subjects

Causa1. Perception Questionnaire

1. Did you enjoy playing the tracking game? Yes No

2. Did you enjoy having people watch you while you played the game?

Yes No

82

3. How did the audience make you feel? Good Bad No Different

Other $\frac{\text { Nervous }}{4}$

4. Did the audience make a difference in how well you played the game?

Yes No

37

a. Did you play better because there were people watching you?

Yes No

37

b. Did you play worse because there were people watching you?

Yes No

19

5. Did the audience think that you played the game well? Yes No

a. Did you play the game as well as they thought? Yes No

b. Did you play the game better than they thought? Yes 3

$\begin{array}{llll}2 & 8\end{array}$

c. Did you play the game worse than they thought? Yes No

6. Would you like to play the gane again? Yes No

73

7. Would you like to have people watch you when you play the game again?

Yes No

$7 \quad 3$

8. Would you like to have people watch you when you play another game

that you like? Yes No

a. What game is $1 \mathrm{t}$ ?

b. Why would you choose that game?

* number of responses

$\mathrm{n}=10$ 
Responses of Experienced

Novel Task Subjects

Causal Perception Questionnaire

1. Did you enjoy plahing the tracking game? Yes No

$10 \% \quad 0$

2. Did you enjoy having people watch you while you played the game? Yes No

$7 \quad 3$

3. How did the audience make you feel? Good Bad No Different Other

4. Did the audience make a difference in how well you played the game? Yes No

28

a. Did you play better because there were people watching you?

Yes No

55

b. Did you play worse because there were people watching you?

Yes No

28

5. Did the audfence think that you played the game well? Yes No

a. Did you play the game as well as they thought? Yes 8 No

b. Did you play the game better than they thought? Yes $\quad \begin{array}{cc}8 & 2 \\ \text { No }\end{array}$

b. Did you play the game beter than they thought? 8

c. Did you play the game worse than they thought? Yes No

6. Would you like to play the game again? Yes No

7. Would you like to have people watch you when you play the game again?

Yes No

$7 \quad 3$

8. Would you like to have people watch you when you play another game that you like? Yes No

a. What game is it?

b. Why would you choose that game?

* number of responses

$\mathrm{n}=10$ 
Total Responses

\section{of Experienced Subjects \\ Causal Perception Questionnaire}

1. Did you enjoy playing the tracking game? Yes No
$20 *$ O

2. Did you enjoy having people watch you while you played the game? Yes No

$\begin{array}{ll}15 & 5 \\ \text { How dj.d the audience make you feel? Good Bad No Different }\end{array}$

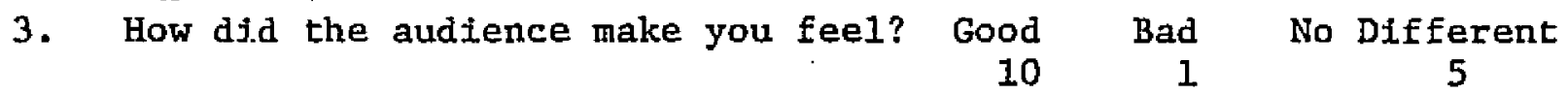
Other Nervous

4. Did the audience make a difference.in how well you played the game?

Yes No

$5 \quad 15$

a. Did you play better because there were people watching you?

Yes No

$8 \quad 12$

b. Did you play worse because there were people watching you?

Yes No

$3 \quad 17$

5. Did the audience think that you played the game well? Yes No

a. Did you play the game as well as they thought? Yes No

b. Did you play the gane better than they thought? Yes 15 No

$\begin{array}{lll}4 & 16\end{array}$

c. Did you play the game worse than they thought? Yes No

6. Would you like to play the game again? Yes No

7. Would you like to have people watch you when you play the game again?

Yes No

8. Would you like to have people watch you when you play another game that you 1ike? Yes No

a. What game is it?

b. Why would you choose that game?

* number of responses

$\mathrm{n}=20$ 
Total. Responses

of Learned Task Subjects

Causal Perception Questionnaire

1. Did you enjoy playing the tracking game? Yes No

2. Did you enjoy having people watch you while you played the game?

Yes No

155

3. How did the audience make you feel? Good Bad No Different Other Nervous

1102

4. Did the audience make a difference in how well you played the game?

Yes No

$5 \quad 15$

a. Did you play better because there were people watching you?

Yes No

$9 \quad 11$

b. Did you play worse because there were people watching you?

Yes No

119

5. Did you audience think that you played the game well? Yes No .

a. Did you play the game as well as they thought? Yes No

. $15 \quad 5$

b. Did you play the game better than they thought? Yes No

c. Did you play the game worse than they thought? Yes 9 No

6. Would you like to play the game again? Yes No

7. Would you like to have people watch you when you play the game again?

Yes No

8. Would you like to have people watch you when you play another game that you like? Yes No

a. What game is it?

b. Why would you choose that game?

* number of responses

$\mathrm{n}=20$ 
Total Responses

of Novel Task Subjects

Causal Perception Questionnaire

1. Did you enjoy playing the tracking game? Yes No

$18 * 2$

2. Did you enjoy having people watch you while you played the game?

Yes No

155

3. How did the audience make you feel? Good Bad No Different Other Nervous

$\begin{array}{lll}\text { II } & 1 & 7\end{array}$

4. Did the audience make a difference in how well you played the game?

Yes No

416

a. Did you play better because there were people watching you?

Yès No

119

b. Did you play worse because there were people watching you?

Yes No

$2 \quad 18$

5. Did the audience think that you played the game wel1? Yes No

a. Did you play the game as well as they thought? Yes No

$\begin{array}{llll}17 & 3\end{array}$

b. Did you play the game better than they thought? Yes No

c. Did you play the game worse than they thought? Yes 11 No

6. Would you like to play the game again? Yes No

7. Would you like to have people watch you when you play the game again?

Yes No

$17 \quad 3$

8. Would you like to have people watch you when you play another game that you like? Yes No

a. What game is it?

b. Why would you choose that game?

* number of responses

$\mathrm{n}=20$ 
VITA

Nancy Lucinda Hollifield was born on January 29, 1951 in Greenville, South Carolina. She attended the public schools of Greenville throughout her youth and in 1968 was graduated from Wade Hampton High School. Majoring in Health and Physical Education, she earned a Bachelor of Arts degree from Furman University in 1972, and in 1973 received a Master of Education Degree from The University of Georgia. After graduation, the author was employed for four years by The School District of Greenvilie County, South Carolina, where she served as an elementary physical education specialist. In 1977 she accepted a teaching assistantship and began two years of doctoral study at Louisiana State University.

Currently employed as a Lecturer by The University of North Carolina at Wilmington, the author holds teaching responsibilities in the areas of elementary physical education curriculum, teaching methodology and gymnastics. 


\section{EXAMINATION AND THESIS REPORT}

Candidate: Nancy Lucinda Hollifield

Major Field: Health, Physical and Recreation Education

Title of Thesis: Effect of Prior Experience Before Audiences on a Dominant and Nondominant Motor Response

Approved:

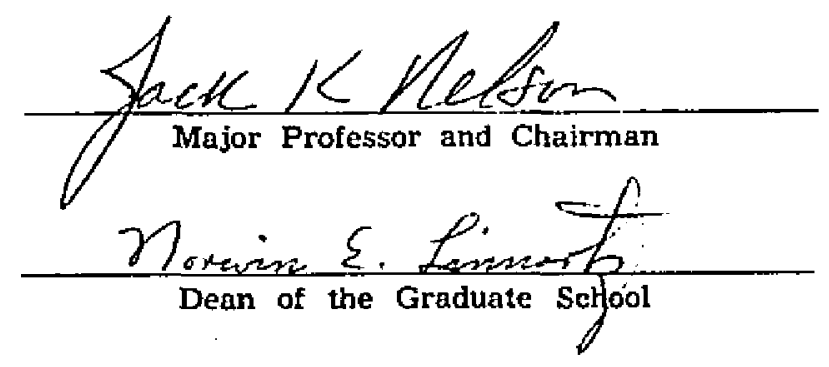

EXAMINING COMMITTEE:
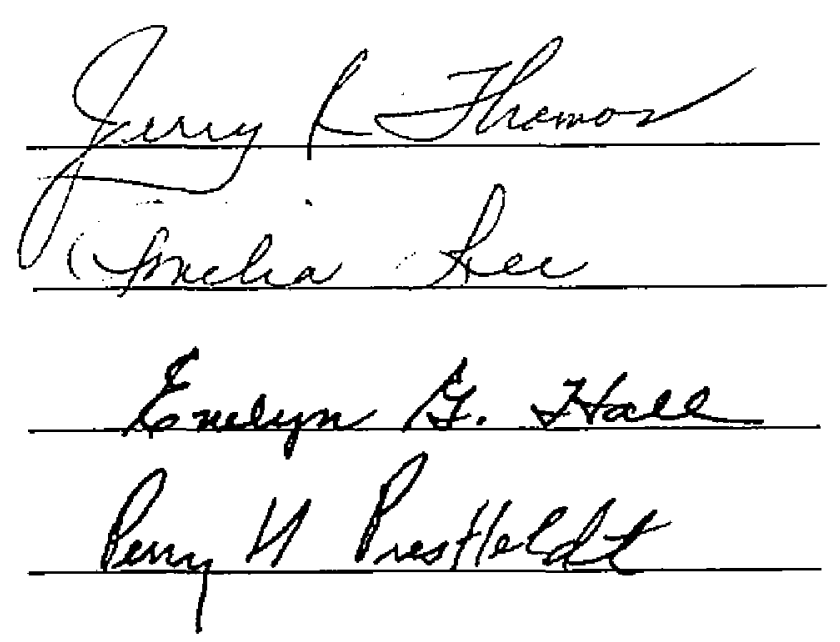

Date of Examination: 